\title{
Higher education institutions as key players to ensure sustainable development goals
}

José Carlos Quadrado, $\mathrm{PhD}^{1}$, Eduarda Pinto Ferreira, $\mathrm{PhD}^{2}$, Yury Pokholkov, $\mathrm{PhD}^{3}$, and Kseniya Zaitseva, $\mathrm{PhD}^{3}$

${ }^{1}$ IPP - Instituto Politécnico do Porto; ISRC - Interdisciplinary Studies Research Center, Porto, Portugal, jcq@ @s.ipp.pt

${ }^{2}$ ISEP - Instituto de Ensino Superior do Porto, IPP, ISRC - Interdisciplinary Studies Research Center, Porto, Portugal, epf@isep.ipp.pt

${ }^{3}$ Third and Fourth Author's EER - Association for Engineering Education of Russia, Moscow, Russian Federation, TPU -

Tomsk Polytechnic University, Tomsk, Russian Federation, pyuori@mail.ru, kkzaitseva@gmail.com

\begin{abstract}
-
Currently, the world community is paying even more attention to sustainable development of our society: moderate consumption, greening and environmentalization of professional activities, responsible resource management, and other aspects that affect nature and society as a whole, as well as the ability to conserve resources for future generations. Considering sustainable development principles is an integral part of training specialists in the field of engineering and technology. Graduates should build their professional activities in accordance with ethical, social, environmental standards, be responsible for the technical decisions they make, be able to forecast and reduce/prevent damage from the technologies they develop. The modern educational process requires adjustments in order to introduce the principles of sustainable development into the training process of engineers. On September 25, 2015, the States Members of the United Nations adopted the Agenda for Sustainable Development until 2030. It contains a number of goals aimed at eradicating poverty, conserving resources of the planet and ensuring well-being for all. Each of the 17 Goals contains a number of indicators to be achieved by 2030. To achieve the Goals in the field of sustainable development, shared efforts of the governments, private sector and civil society are needed. Education is recognized as the most important mechanism for ensuring sustainable social and economic development. The wide recognition of the education and closely related

upbringing and enlightenment as a decisive factor has made it necessary not only to consider the main issues related to the ecology and social responsibility in the process of training of engineers but also foster the sustainable development mindset of the students.
\end{abstract}

\section{INTRODUCTION}

The concept of sustainable development owes its existence to the understanding of extreme importance of global challenges and the importance of finding new ways to solve them. Sustainable development is highlighted in the goals of the leading international organizations - the United Nations, the World Bank, the World Trade Organization, etc $[1,2]$. On September 25, 2015, the States Members of the United Nations adopted the Agenda for Sustainable Development until 2030. It contains a number of goals aimed at eradicating poverty, conserving resources of the planet and ensuring well-being for all. Each of the 17 Goals contains a number of indicators to be achieved by 2030 . To achieve the Goals in the field of sustainable development, shared efforts of the governments, private sector and civil society are needed.

Education is recognized as the most important mechanism for ensuring sustainable social and economic development. The wide recognition of the education and

Digital Object Identifier (DOI):

http://dx.doi.org/10.18687/LACCEI2019.1.1.211

ISBN: 978-0-9993443-6-1 ISSN: 2414-6390 closely related upbringing and enlightenment as a decisive factor has made it necessary not only to consider the main issues related to the ecology and social responsibility in the process of training of engineers but also foster the sustainable development mindset of the students.

\section{ENGINEERING EDUCATION AND SUSTAINABLE DEVELOPMENT}

The concept of sustainable development embraces three aspects - economic, social, and ecological, and is determined as "development that meets the needs of present generations without jeopardizing the ability of futures generations to meet their own needs". The key role in understanding and preventing the challenges of the environment, i.e. "the sustainable development", can be played by the education, and in particular, the engineering education, through fostering corresponding behavior and actions, for instance, on research and development of new solutions, products and technologies allowing to reduce the use of energy and gas, $\mathrm{CO} 2$ emission, soil erosion, etc.

Professional actions of engineers influence directly the quality of life of the mankind; therefore, the actions of engineers require honesty, impartiality, justice and efficiency. Their actions have to be aims at health protection, safety and wellbeing of people. It is not a coincidence that in the modern world exist and develop such trends as Responsible Research and Innovations, Responsible Industry, Technology Assessment [3], etc.

We can assume that an integrating condition for the realization of any of these trends is not only the formation of the competences of each person (specialist), participating in the decision making process. It is dramatically important to manage development of sustainability mindset and social responsibility competence. These conditions cannot be met without active and decisive contribution of the education system at all stages. New models for sustainable education must be aimed at changing the mindsets of future generations beginning at an early age then fostered through formal education at undergraduate, graduate and professional levels.

The scientific challenges of sustainability on which governments, private sector and civil society should focus their efforts represent only one part of the necessary social transition to a sustainable society. Universities can play a pivotal role in addressing the more difficult yet critical aspect of the sustainability transition. That role is in creating and maintaining a specific environment of sustainable development at university, which can serve as a model for what is needed in cities and in the corporate world. 
Engineering influences directly the quality of life of the mankind; therefore, the actions of engineers require honesty, impartiality, justice and efficiency. Their actions have to be aims at health protection, safety and wellbeing of people.

Fostering a socially-oriented mindset and behavior of future engineers requires from the educational organizations and educational process to implement adjustments in order to introduce the principles of sustainable development into the training process of engineers.

Introduction of the competence-based approach to the designing of educational programs is a necessary, but not sufficient condition required to guarantee the expected level of future specialists' competences of social responsibility within the educational process. The pivotal factors ensuring the formation of required competences within the educational process are the teaching and learning methods and conditions for their implementation (including the potential and qualification of faculty) and the specific university environments that support fostering of competences.

Specific environments such as "ecological environment", "environment forming responsibility", "creative (innovative) environment", etc., create the basis for the development of relevant competencies at university, both for students and teachers, and for managerial staff. Orientation of the university on purposeful formation of specific environments will allow in a more successful way and in a shorter period of time to implement qualified training of graduates in the field of engineering and technology that meet the requirements of the labor market and the modern society as a whole.

The promotion and abidance of sustainable development ideas in individual and public consciousness largely depends on the proper completion of above stated tasks. This means that only those projects that "work" for the preservation of health, well-being of people, taking into account the factors of environmental impact, can and should be regarded as actual technical achievements of engineering.

Despite the recognition of the importance of reforming education systems for ensuring sustainable development, the efforts are not successful enough. This is partly due to the fact that pedagogical traditions are based on the transfer of existing knowledge, the reproduction of real connections and attitudes reflected in the public consciousness. The future is always more or less uncertain. This fact determines, in essence, the establishment of fundamentally new pedagogical and management tasks related to the formation of a sustainable development mindset.

The purpose of the present study is the description of an innovative teaching project at higher education level, particularly, the implantation of flipped classroom in specific subjects for the next generation of practitioners that will creatively implement the Sustainable Development Goals (SDG's) by 2030.

\section{A. Context and students}

Digital Object Identifier: (to be inserted by LACCEI).

ISSN, ISBN: (to be inserted by LACCEI).
The innovative teaching project will be applied at Instituto Politécnico do Porto (P.PORTO), in the Masters in Development Practice programme (MDP). The degree is composed of 2 academic years including a field practice and dissertation/internship in the second year.

This programme was designed to be fully compatible with the other existing MDP's including the joint offered global classroom to reinforce the potential of the outstanding students in order to help them to achieve the highest academic and practitioner performance required in the second year of this master course.

The teaching project will be applied in the two "Foundation: Analysis, Conceive and Design" subjects, which correspond two semester courses (a total of 10 ECTS) in the first year of the MDP. The subject is considered as an interdisciplinary training course (Quadrado \& Zaitseva, 2017) that better prepares the students for the practitioner work.

\section{B. Learning goals and outcomes}

The teaching project has been designed to develop the following learning goals and outcomes (Table 1).

TABLE I

LEARNING GOALS AND LEARNING OUTCOMES PROPOSED

\begin{tabular}{|l|l|}
\hline \multicolumn{1}{|c|}{ Learning Goals } & \multicolumn{1}{c|}{ Learning Outcomes } \\
\hline Learning by Experience & Apply the SDG's concepts in field \\
\hline Learning to Learn & $\begin{array}{l}\text { Be able to perform an experimental } \\
\text { design }\end{array}$ \\
\hline Critical Thinking & $\begin{array}{l}\text { Be able to summarize and present to peers } \\
\text { a research article }\end{array}$ \\
\hline \multirow{2}{*}{ Logical Thinking } & $\begin{array}{l}\text { Be able to apply the theoretical } \\
\text { knowledge in a practical case }\end{array}$ \\
\cline { 2 - 3 } & $\begin{array}{l}\text { Be able to solve complex problems by } \\
\text { applying the knowledge acquired }\end{array}$ \\
\hline
\end{tabular}

\section{Participants and class process}

Before the inclusion of this methodology in the Foundations subjects, by design, included ten seminars, which consisted of: global classroom presentations in the classroom by international specialist on a specific SDG's topic in addition to local experts in relation to the latest national state-of-the-art in relation to the same subject.

The teaching activities, here described, will be carried out from October to June, taking place one per every two months. The material will be delivered through the P.Porto proprietary on-line educational platform, DOMUS, which integrates the Moodle and is available for both students and teachers. This educational platform includes a great variety of options, such as a description of teaching guide, calendar, gradebook, announcements and different tools for communicating with the students: mail or chat (forums). Also, it includes a folder with resources, and a section to perform tests/quizzes and assignments. 
Also, this platform will allow the delivery of the material, such as scientific articles, guidelines for the activities, extra-material, screencasts or exercises, but also the students will be able to upload their posters, presentations or any other assignments requested. A forum will be created to enhance the communication not only with the teacher responsible for the activities but also among classmates.

\section{Teaching activities and Assessment}

The teaching activities have been designed in order to enhance the following: learning outcomes, knowledge to learn and skills to develop.

The five teaching activities total $15 \%$ of the full subject score. After each activity and prior to the next one, the teacher will deliver the individual marks to be consulted by each student.

With the aim of motivating the students, the teaching project includes an innovative methodology of assessment, namely, gamification. As if it were a game, the students will be ranked depending on the mark they have obtained after each activity. We will establish three categories: the 33\% with the best marks will be placed in the first category, the following 33\% of the best marks in the second category, and the rest in the third category. Those students who are located in the first category will achieve the maximum score $(15 \%)$, the students placed in the second category will achieve $10 \%$ and the last ones will be given 5\%. However, in order not to punish any students excessively, the teacher responsible for the activity will be able to increase the mark up to $3 \%$ more for those students who have accomplished the learning goals.

The individual score will depend on the indicators of achievement for each learning.

Task 1 - Learning based on projects: Apply the SDG's concepts in field

Based on a real case ("field practicum" previous projects) outside of the classroom, the students should be able analyze how to proceed in specific situations in the terrain. Once in the classroom, the teacher responsible for the activity will comment on the most common errors and possible doubts and it will be possible to open a discussion about the ethical needs to act accordingly during "field practicum" experimentation.

Learning outcome: Apply the targets of the SDG's in a field practicum experimentation

Knowledge to learn: The SDG's objectives and targets

Skills to develop: Autonomy and personal initiative.

Description of the indicators of achievements:

- Knows how to apply the local rules and regulations during the "field practicum";

- Is able to identify the most relevant SDG's to intervene upon;

- Has been demonstrated autonomy to develop the activity.
Task 2 - Carry out your own experimental design

The design of experiments including living beings is a responsibility and needs prior knowledge. The students, in groups of 2, will design a field practicum experiment following the guidelines of the activity, which later on will be presented in classroom through ICTs. The teachers will point out the possible errors or doubts after each presentation.

Learning outcome: Be able to perform an experimental design.

Knowledge to learn: Learn the basic principles of designing a field practicum experiment including how to relate to the surroundings in a real field practicum situation.

Skills to develop: Oral communication, teamwork, creativity.

Description of the indicators of achievements:

- Know how to design a feasible experiment;

- Know the procedure of designing an experiment including living beings;

- Show creativity;

- Develop oral skills.

Task 3 - Show me what you know

The ability to obtain the most relevant information and show it in an attractive manner is a difficult task which requires specific training. The students, in groups of 2 , will elaborate a scientific poster from a research article following the criteria described in the guidelines. In the classroom, after students give a brief description of the research described in the poster, the teacher will point out the possible errors and improvements.

Learning outcome: Be able to summarize and explain in a presentation, a research article

Knowledge to learn: Learn how to obtain the most relevant information from a scientific article

Skills to develop: Synthesis, creativity and oral communication

Description of the indicators of achievements:

- Ability to synthesize;

- Improve the reading comprehension of scientific literature;

- Show creativity;

- Develop oral skills.

Task 4 - Development Goals on internet

Internet provides a huge amount of information and is a powerful tool for both students and educators. Nevertheless, it is necessary to be extremely critical and verify if the information can be used or trusted. Taking this idea as the basis, the students (in groups of 2) should search internet (digital press, blogs, chats...) for relevant news in relation to the subject, making an oral presentation in the classroom showing a list of possible fake news items in contrast to others that can be trusted. Once the presentation is finished,

17" LACCEI International Multi-Conference for Engineering, Education, and Technology: "Industry, Innovation, And Infrastructure for Sustainable Cities and Communities”, 24-26 July 2019, Jamaica. 
an open discussion will be initiated concerning the dangers presented by fake news in relation to health.

Learning outcome: Be able to apply the theoretical knowledge in a practical case.

Knowledge to learn: Learn to contrast the information.

Skills to develop: Critical thinking, ability to seek information.

Description of the indicators of achievements:

- Ability to find information;

- Critical thinking;

- Ability to transfer theoretical knowledge to resolve practical cases.

Task 5 - Find out who is to blame

One of the most difficult tasks is to apply the theory to solve a real problem. In the current activity, the students will watch recorded videos in relation to the effects of interventions in the society. Later on, in the classroom, the teacher will provide the students (in groups of 2) with the description of a disease. The task will consist in finding out which are the causes of the problems and which actors are involved.

Learning outcome: Be able to solve complex problems by applying the knowledge acquired.

Knowledge to learn: Learn how to impact the society.

Skills to develop: Logical and deductive thinking.

Description of the indicators of achievements:

- Ability to solve complex problems;

- Ability to transfer theoretical knowledge to resolve practical cases;

- Develop logical thinking;

- Improve deductive skills.

A suitable solution for the problem is what will be evaluated, which will be delivered to the teacher responsible for the activity before the discussion of the different answers and the correct solution in the classroom.

\section{CONCLUSIONS}

One of the core and fundamental principles of sustainable development is responsible consuming of natural resources in order to maintain and better to increase them for future generations. The implementation of this principle is not possible without formation of a special world outlook of each member of society - the mindset of responsibility for the expenditure of resources and conditions regulating the use of resources. Essentially, it involves social responsibility of each member of our society and communities at large (companies, enterprises, public organizations and others). This personal and corporate responsibility includes social consequences of all their activities and all kinds of their decisions concerning not only consuming exhaustible resources and resource saving, but also measures taken to create conditions necessary for this.

The aim of the present innovative teaching project is to help students to acquire a deeper knowledge of the syllabus and extra motivation. With the aim of reaching these goals, an educational methodology known as flipped classroom has been proposed to be applied in Foundations of the Masters in Development Practice programme.

Taking as the basis the inverted classroom model, up to 5 activities, individual and in groups, have been designed with the objective of developing high-order cognitive competences, such as critical or logical thinking.

In order to evaluate the teaching project effectiveness, we will compare the score of the groups within the seminars with the aim of observing if the new educational strategy has had an impact on the results of the whole subject.

Finally, motivation will be evaluated through an anonymous questionnaire, in which the students will be asked about the level of satisfaction of the teaching programme, which activities they considered more attractive and which aspects they would change in the future.

The results achieved in similar environments show that this can be a solution which involves some extra upfront work and just might not mesh with the teaching style of every educator. But many of the educators that have tried it, found it worthwhile to experiment with flipping some lessons to see what the results are.

\section{REFERENCES}

[1] World Commission on Environment and Development, 1987. Our Common Future. Oxford University Press, Oxford (1987)

[2] The World Bank Report. (2001) Constructing Knowledge Societies: New Challenges for Tertiary Education. Washington, DC: The World Bank

[3] Grunwald, A., Wyss, M., Peppoloni, S.: The imperative of sustainable development: elements of an ethics of using geo-resources responsibly. Geoethics. Ethical challenges and case studies in earth sciences, pp. 2635. Elsevier, Amsterdam (2015)

[4] AZEVEDO, R. (2005). "Computer Environments as Metacognitive Tools for Enhancing Learning." Educational Psychologist, 40(4), 193197.

[5] BREWER, R., ANTHONY, L., BROWN, Q., IRWIN, G., NIAS, J., \& TATE, B. (2013). "Using Gamification to Motivate Children to Complete Empirical Studies in Lab Environments." In Proceedings of the 12th International Conference on Interaction Design and Children (pp. 388391). New York, NY, USA: ACM.

[6] DAVIES, R. S., DEAN, D. L., \& BALL, N. (2013). "Flipping the classroom and instructional technology integration in a college-level information systems spreadsheet course." Educational Technology Research and Development, 61(4), 563-580.

[7] DAVIES, R. S., \& WEST, R. E. (2014). "Technology Integration in Schools." In J. M. Spector, M. D. Merrill, J. Elen, \& M. J. Bishop (Eds.), Handbook of Research on Educational Communications and Technology (pp. 841-853). New York, NY: Springer New York.

[8] DETERDING, S., DIXON, D., KHALED, R., \& NACKE, L. (2011). "From game design elements to gamefulness: Defining gamification." Proceedings of the 15th International Academic MindTrek Conference on Envisioning Future Media Environments - MindTrek '11, 9-11. 
[9] FITZ-WALTER, Z., TJONDRONEGORO, D., \& WYETH, P. (2011). "Orientation Passport: using gamification to engage university students." Proceedings of the 23rd Australian Computer-Human Interaction Conference on - OzCHI '11, 122-125.

[10]Flatla, D. R., GUTWIN, C., NACKE, L. E., BATEMAN, S., \& MANDRYK, R. L. (2011). "Calibration games: making calibration tasks enjoyable by adding motivating game elements." Proceedings of the 24th Annual ACM Symposium on User Interface Software and Technology UIST '11, 403-412.

[11]HSU, H.-Y., WANG, S.-K., \& RUNCO, L. (2013). "Middle School Science Teachers' Confidence and Pedagogical Practice of New Literacies." Journal of Science Education andTechnology, 22(3), 314324.

[12]HUOTARI, K., \& HAMARI, J. (2012). "Defining gamification." Proceeding of the 16th International Academic MindTrek Conference on MindTrek '12, 17.

[13]IOSUP, A., \& EPEMA, D. (2014). "An experience report on using gamification in technical higher education." Proceedings of the 45th ACM Technical Symposium on Computer Science Education - SIGCSE '14, (2008), 27-32.

[14]KHAN, S. (2012). The one world schoolhouse: Education reimagined. London: Hodder and Stoughton.

[15]LAJOIE, S. P., \& AZEVEDO, R. (2000). "Cognitive tools for medical informatics." Computers as Cognitive Tools II: No More Walls: Theory Change, Paradigm Shifts and Their Influence on the Use of Computers for Instructional Purposes, 247-271.

[16]NELSON, M. J. (2012). "Soviet and American precursors to the gamification of work. "Proceeding of the 16th International Academic MindTrek Conference on - MindTrek'12, 23.

[17]POKHOLKOV Y.\& ZAITSEVA K. Specific learning environments for fostering students' sustainability mindset [Electronic resources] // 45th SEFI Annual Conference 2017: Education Excellence for Sustainability: Proceedings, p. 223-228

[18]QUADRADO J. C. \& ZAITSEVA K. Engineering education interdisciplinarity in global teams [Electronic resources] // 45th SEFI Annual Conference 2017: Education Excellence for Sustainability: Proceedings, , p. 954-961.

[19]TALBERT, R. (2012). "Inverted classroom." Colleagues, 9(1, Article 7), $1-2$.

[20]THOMASIAN, J. (2012). "Building a science, technology, engineering and math education agenda: an update of state actions." National Governors Association Center for Best Practices.

[21]WANG, S. K., HSU, H. Y., REEVES, T. C., \& COSTER, D. C. (2014). "Professional development to enhance teachers' practices in using information and communication technologies (ICTs) as cognitive tools: Lessons learned from a design-based research study." Computers and Education, 79, 101-115. 